\title{
Areca Palm Necrotic Ringspot Virus, Classified Within a Recently Proposed Genus Arepavirus of the Family Potyviridae, Is Associated With Necrotic Ringspot Disease in Areca Palm
}

\author{
Ke Yang, ${ }^{1}$ Wentao Shen, ${ }^{2}$ Ye Li, ${ }^{3}$ Zengping Li, ${ }^{1}$ Weiguo Miao, ${ }^{1}$ Aiming Wang, ${ }^{4}$ and Hongguang Cui $1, \dagger$ \\ ${ }^{1}$ Key Laboratory of Green Prevention and Control of Tropical Plant Diseases and Pests, Ministry of Education and College of Plant Protection, \\ Hainan University, Haikou, Hainan 570228, China; ${ }^{2}$ Institute of Tropical Bioscience and Biotechnology, Chinese Academy of Tropical \\ Agricultural Sciences, Haikou, Hainan 571101, China; ${ }^{3}$ Environment and Plant Protection Institute, Chinese Academy of Tropical \\ Agricultural Sciences, Haikou, Hainan 571101, China; and ${ }^{4}$ London Research and Development Centre, Agriculture and Agri-Food Canada, \\ London, Ontario N5V 4T3, Canada \\ Accepted for publication 3 October 2018.
}

\section{ABSTRACT}

Areca palm (Areca catechu), one of the two most important commercial crops in Hainan, China, has been severely damaged by a variety of pathogens and insects. Here, we report a new disease, tentatively referred to as areca palm necrotic ringspot disease (ANRSD), which is highly epidemic in the main growing regions in Hainan. Transmission electron microscopy observation and small RNA deep sequencing revealed the existence of a viral agent of the family Potyviridae in a diseased areca palm plant (XC1). The virus was tentatively named areca palm necrotic ringspot virus (ANRSV). Subsequently, the positive-sense single-stranded genome of ANRSV isolate XC1 was completely determined. The genome annotation revealed the existence of two cysteine proteinases in tandem (HC-Prol and
HC-Pro2) in the genomic 5' terminus of ANRSV. Sequence comparison and phylogenetic analysis suggested the taxonomic classification of ANRSV into the recently proposed genus Arepavirus in the family Potyviridae. Given the close relationship of ANRSV with another newly reported arepavirus (areca palm necrotic spindle-spot virus), the exact taxonomic status of ANRSV needs to be further investigated. In this study, a reverse transcription polymerase chain reaction assay for ANRSV-specific detection was developed and a close association between ANRSV and ANRSD was found.

Keywords: Areca catechu, HC-Pro, Potyviridae.
Areca palm (Areca catechu L.), a species in the botanical family Arecaceae (palm), is widely distributed in Southern and Southeast Asia (Peng et al. 2015). The areca nut of areca palm is a popular chewable fruit and is also used in traditional Chinese medicine (Amudhan et al. 2012; Heatubun et al. 2012; Peng et al. 2015). Areca palm fruits possess antiparasitic compounds, promote digestion, and show an antidepressive effect (Peng et al. 2015). Areca palm is the second largest commercial crop in Hainan, China. Unfortunately, it has been severely damaged by a variety of insects and pathogens, such as Brontispa longissima, Tirathaba rufivena, and phytoplasma (Kanatiwela-de Silva et al. 2015; Ramaswamy et al. 2013; Zhang et al. 2015; Zhong et al. 2017). Areca palm velarivirus 1, identified from yellowing leaves of areca palm in Hainan, China, was the first virus reported in this host (Yu et al. 2015). Recently, our group characterized another virus (areca palm necrotic spindle-spot virus [ANSSV]) from a diseased areca palm plant showing chlorotic symptoms in new leaves and necrotic spindle-spots in the medium and bottom leaves (Yang et al. 2018). Analysis of its complete genomic sequence suggests ANSSV to be

†Corresponding author: H. Cui; hongguang.cui@ hainu.edu.cn

Funding: This study was financially supported by Hainan Major Research Fund of science and technology (No. ZDKJ201817), Central Public-interest Scientific Institution Basal Research Fund for Chinese Academy of Tropical Agricultural Sciences (No.19CXTD-33) and the Scientific Research Foundation for Advanced Talents, Hainan University (No. KYQD(ZR)

K. Yang and W. Shen contributed equally to this work.

*The $\boldsymbol{e}$-Xtra logo stands for "electronic extra" and indicates that two supplementary figures and six supplementary tables are published online.

The author(s) declare no conflict of interest.

C 2019 The American Phytopathological Society the first member of a putative new genus of the family Potyviridae, called Arepavirus (Yang et al. 2018).

The Potyviridae is the largest family of plant-infecting RNA viruses and includes many agriculturally and economically important viral pathogens causing significant losses in a wide range of crops (Revers and García 2015; Wylie et al. 2017a). Currently, the family consists of 10 definitive genera (i.e., Potyvirus, Brambyvirus, Bymovirus, Ipomovirus, Macluravirus, Poacevirus, Rymovirus, Tritimovirus, Roymovirus, and Bevemovirus) distinguished by host range, genomic features, and phylogeny (Lockhart et al. 2011; Mollov et al. 2013; Seo et al. 2017; Wylie et al. 2017a, 2017b). Except for bymoviruses, which have bipartite genomes with particles of two modal lengths of 250 to $300 \mathrm{~nm}$ and 500 to $600 \mathrm{~nm}$, other viruses in the family have monopartite, positive-sense, and single-stranded RNA genomes $(8.2$ to $11.3 \mathrm{~kb})$ and 11 - to $20-\mathrm{nm} \times 680$ to 900-nm flexuous filamentous particles (Wylie et al. 2017a). For most members of the family, the RNA genome contains a long open reading frame (ORF) encoding a single polyprotein that is cleaved into 10 functional mature proteins by three self-encoded proteases (Wylie et al. 2017a). The bipartite genomes of bymoviruses encode two polyproteins that are cleaved by two proteases (Adams et al. 2005b; Wylie et al. 2017a). Another relatively short ORF (PIPO), resulting from RNA polymerase slippage in the P3 coding sequence, is expressed as the trans-frame protein P3N-PIPO (Chung et al. 2008; Olspert et al. 2015; Rodamilans et al. 2015).

The genome organization of viruses in the family Potyviridae is highly conserved in the central and carboxy-terminal regions of the polyprotein that starts at the P3 cistron, which is also the case with the polyprotein encoded by RNA1 of bymoviruses (Valli et al. 2017). In contrast, the upstream genomic $5^{\prime}$ terminus is highly variable and encodes proteins that are liberated from the polyprotein precursors by their self-cleavage (Valli et al. 2017). P1 protein, a chymotrypsin-like serine protease located at the beginning of viral polyprotein, is believed to be the most divergent protein 
(Rodamilans et al. 2013; Rohožková and Navratil 2011). The majority of viruses in the family have one P1 protein, some ipomoviruses code for two P1 proteins, and all known macluraviruses lack the $\mathrm{P} 1$ protein (Hu et al. 2018; Minutillo et al. 2015; Rodamilans et al. 2013; Shan et al. 2018; Valli et al. 2007). This hypervariable amino-terminal region is closely related to its functional roles in viral infection. Generally, P1 is responsible for its cis-cleavage at the P1/HC-Pro junction and thus self-releases from the polyprotein (Adams et al. 2005a). P1's self-cleavage is indispensable for viral viability and host range specificity (Pasin et al. 2014; Shan et al. 2015). Intriguingly, the P1 proteins of a tritimovirus (wheat streak mosaic virus) and two poaceviruses (triticum mosaic virus and sugarcane streak mosaic virus) function in the suppression of RNA silencing (RSS) (Tatineni et al. 2012; Young et al. 2012). For the majority of viruses of this family, another protein following $\mathrm{P} 1$ protein and located in the genomic $\mathrm{N}$ terminus is HC-Pro, which is currently classified in the C6 peptidase superfamily (Rawlings et al. 2016). Many previous studies demonstrated that the most outstanding feature of HC-Pro from potyviruses and rymoviruses is its RSS activity. However, the sweet potato-infecting potyviruses express an apparently normal HC-Pro variant that has no evident RSS activity (Valli et al. 2017). Remarkably, HC-Pro is missing for most ipomoviruses.

In this study, we report a new disease and a likely new virus that are closely associated. The virus is tentatively named areca palm necrotic ringspot virus (ANRSV) and is phylogenetically classified into the recently proposed genus Arepavirus in the family Potyviridae. The genome annotation reveals the existence of two cysteine proteinases in tandem (HC-Pro1 and $\mathrm{HC}$-Pro2) in the genomic $5^{\prime}$ terminus of ANRSV. Studies and characteristics of ANRSV will help in the effective management of areca palm necrotic ringspot disease (ANRSD) affecting the economically important areca palm.

\section{MATERIALS AND METHODS}

Field survey. During the period of June 2017 to March 2018, a field survey of the incidence of ANRSD was carried out in eight main growing regions in Hainan, China: Dingan, Qionghai,

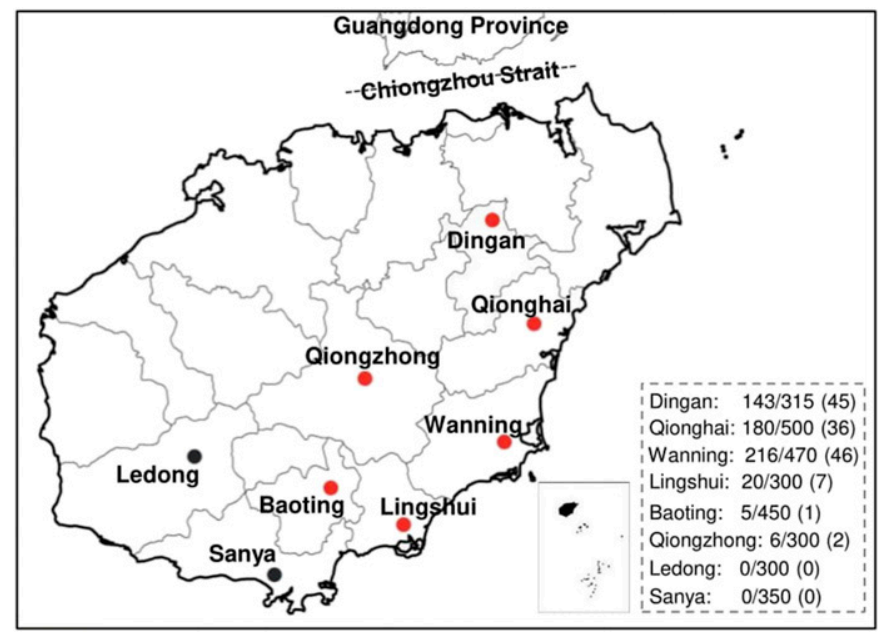

Fig. 1. A map showing the occurrence and distribution of areca palm necrotic ringspot disease (ANRSD) in eight growing regions in Hainan, China. The regions marked with gray/red and black dots indicate the existence and absence of ANRSD, respectively. The rectangular panel on the lower right shows the results of statistical analysis on the incidence rate of ANRSD in each growing region. For each region, the numbers of the diseased and surveyed areca palm plants as well as the incidence of ANRSD (\%) are shown. For example, the data set "Dingan: 143/315 (45)" means that the numbers of the diseased and surveyed plants in Dingan are 143 and 315, respectively, and the incidence of ANRSD is $45 \%$.
Wanning, Lingshui, Baoting, Qiongzhong, Ledong, and Sanya (Fig. 1). For each region, at least three dispersed areca palm orchards were subjected to the survey, and 100 to 150 areca palm plants ( $>5$ years old) in each orchard were randomly selected to evaluate the incidence of ANRSD. The areca palm plants displaying obvious necrotic ringspot symptoms (Fig. 2A) were judged to be the diseased plants.

Plant materials. In June 2017, leaf samples exhibiting typical necrotic ringspot symptoms (Fig. 2A) were collected from a diseased areca palm plant (XC1) grown in one orchard in Qionghai, Hainan (Fig. 1), and were used as sources for transmission electron micrographs, small RNA (sRNA) deep sequencing, and determination of the complete genomic sequence. To study the genetic diversity of ANRSV, leaf samples of a total of 30 diseased areca palm plants were collected from four main growing regions with a high incidence rate of ANRSD, including six from Dingan, 11 from Qionghai, 11 from Wanning, and two from Lingshui (Fig. 1), and subjected for cloning of the complete coat protein (CP) genes of ANRSV. For the association study of ANRSV with ANRSD, an additional 15 diseased samples (eight from Baoting and seven from Qiongzhong) and 20 asymptomatic samples from the healthy areca palm orchards located in the eight main growing regions were collected (Fig. 1).

Electron microscopy. Transmission electron microscopy was employed to screen the potential viral agent in the diseased areca palm plant (XC1). Briefly, the fresh leaf tissue of $\mathrm{XC} 1$ and sterilized pure water were mixed at a ratio of 1:10 (in $\mathrm{g} / \mathrm{ml}$ ) and ground with a mortar and pestle. The mixture was placed on ice for $5 \mathrm{~min}$, and the resulting supernatant was immediately dropped onto copper grids (200-mesh), followed by absorption for $2 \mathrm{~min}$ and negative staining with $1 \%$ phosphotungstic acid for $2 \mathrm{~min}$. Then the copper grids were dried under a tungsten lamp for $\sim 30$ min and examined with a transmission electron microscope (HT-7700; Hitachi). The diameter or length of the particles was determined by 30 measurements using Adobe Photoshop CS3 software and was statistically analyzed by SAS software (version 9.2).

sRNA library construction and deep sequencing. Total RNA from fresh leaf samples of XC1 was extracted with TRIzol (Invitrogen), and the sRNA molecules in a size range of 16 to $30 \mathrm{nt}$ were enriched by polyacrylamide gel electrophoresis ( $\mathrm{Li}$ et al. 2016a). An sRNA library was constructed using a TruSeq Small RNA Library Prep Kit (Illumina), followed by deep sequencing using the Illumina HiSeq 2500 System (Genedenovo Biology Technology Ltd.). The raw reads were filtered for quality, reduced to unique reads, and de novo assembled into larger contigs using Velvet software (version 1.2.08) (Zerbino and Birney 2008) with a $k$-mer of 17. After assembly, the obtained contigs were subjected to BLASTx search against the National Center for Biotechnology Information (NCBI) GenBank nonredundant protein database.

Determination of the complete genomic sequence of ANRSV. To confirm the entire genome of ANRSV, nine fragments covering the nearly complete genome were amplified using reverse transcription (RT) polymerase chain reaction (PCR) with primer sets (Supplementary Table S1) designed on the basis of the sequences and relative positions of contigs mapped in the genomic RNAs of the closely related macluraviruses. The $5^{\prime}$ - or $3^{\prime}$-terminal cDNAs were obtained using a $5^{\prime}$ - or $3^{\prime}$-rapid amplification of cDNA ends (RACE) kit (Invitrogen) according to the manufacturer's instructions. Total RNA was extracted from symptomatic leaf samples of XC1 with the RNAprep Pure Plant Kit (Tiangen), and the first-strand cDNAs were synthesized by RT reactions using a RevertAid First Strand cDNA Synthesis Kit with random hexamer primers (Thermo Fisher Scientific). PCR was carried out using Thermo Scientific Phusion High-Fidelity DNA Polymerase (Thermo Fisher Scientific); the resulting PCR products were cloned into pTOPO-Blunt vector (Aidlab Biotechnologies), and three independent positive clones of each fragment were subjected to Sanger sequencing (Sangon Biotech). Overlapping sequences were 
assembled using Seqman Pro 7.1.0 software (Lasergene; GATC Biotech) to obtain the complete genomic sequence of ANRSV.

Sequence analysis. Nucleotide sequence analysis, such as sequence assembling and ORF analysis, was carried out using the Lasergene software package (version 7.1). Pairwise comparison and calculation of amino acid or nucleotide sequence identities was carried out using ClustalW2 (https://www.ebi.ac.uk/Tools/msa/clustalw2/). A conserved domain (CD) search was performed using the NCBI Conserved Domains online analysis program (https://www.ncbi.nlm. nih.gov/Structure/cdd/wrpsb.cgi) (Marchlerbauer et al. 2017).

Phylogenetic analysis. A pair of primers (CP-forward $[\mathrm{F}]$ and $\mathrm{CP}$-reverse $[\mathrm{R}]$ ) located in the $3^{\prime}$ terminus of the NIb cistron and the
3' untranslated region (UTR) of ANRSV isolate XC1, respectively, were designed and used for the amplification, cloning, and sequencing of the complete CP gene by RT-PCR as described above. Multiple alignment of nucleotide sequences of the $\mathrm{CP}$ gene of 27 ANRSV isolates was carried out with ClustalX 1.8.1 (http:// www.clustal.org), and a phylogenetic tree was constructed with the maximum-likelihood method using MEGA7.0.20. The collection regions and GenBank accession numbers of these isolates are listed in Table 1. The robustness of the inferred evolutionary relationships was assessed by 1,000 bootstrap replicates. For the construction of the phylogenetic tree based on the amino acid sequences of polyprotein of viruses in the Potyviridae family, the amino acid
A

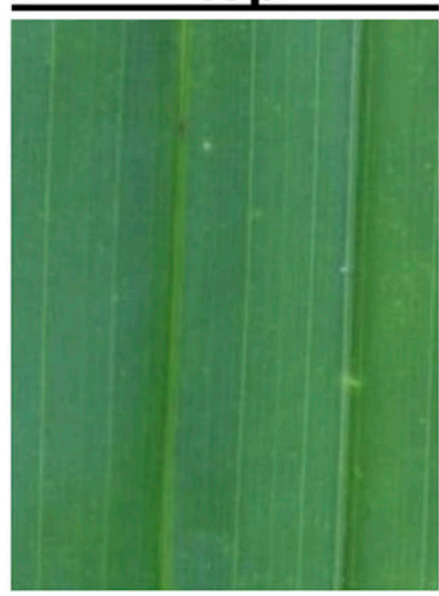

B

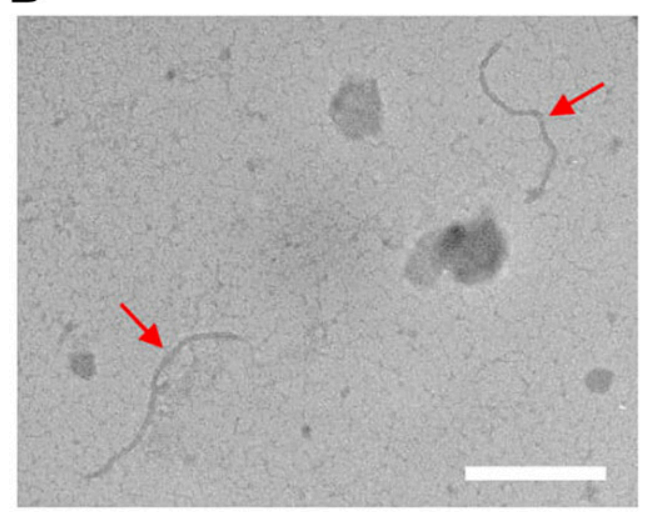

middle

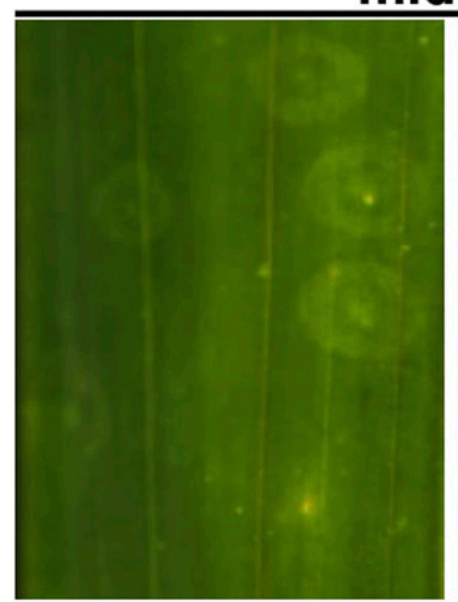

bottom
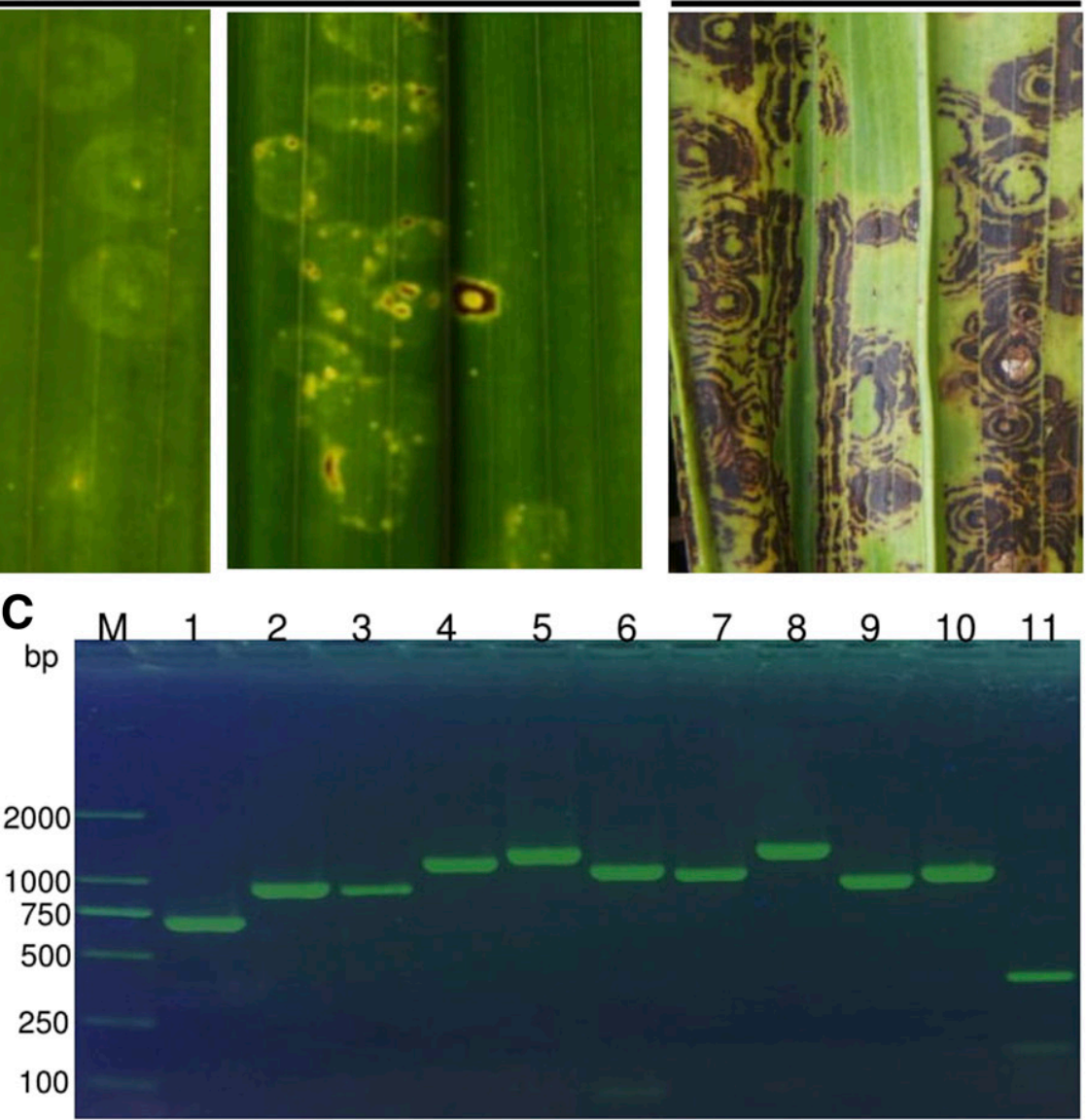

D

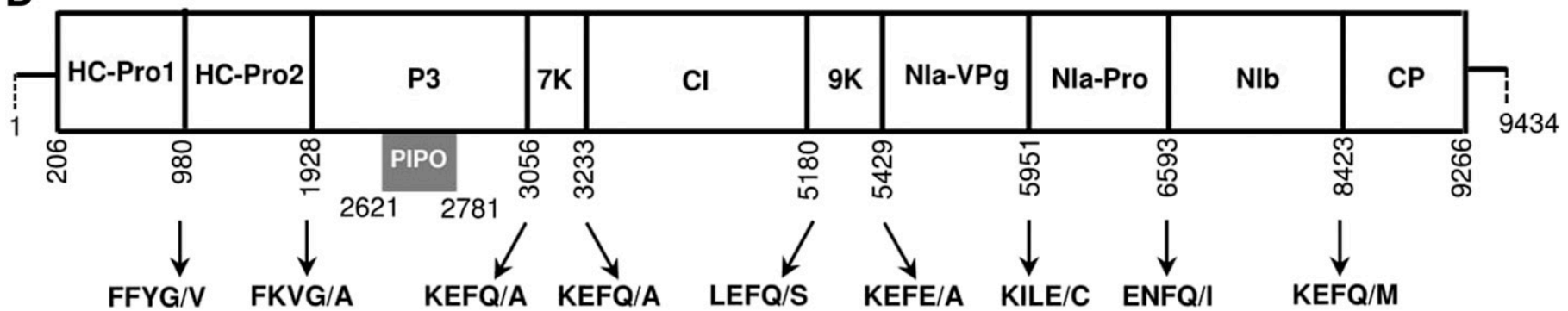

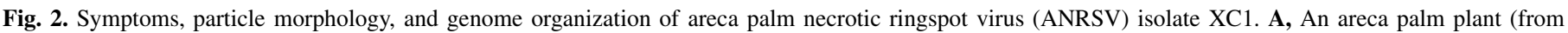

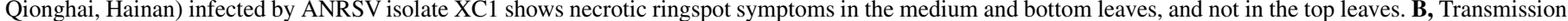

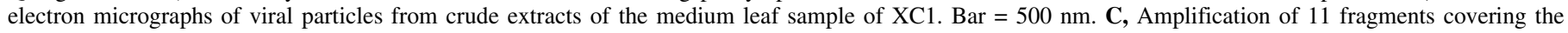

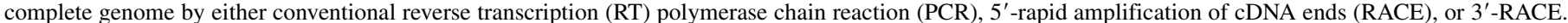

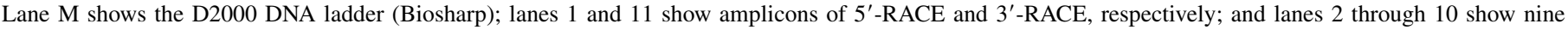

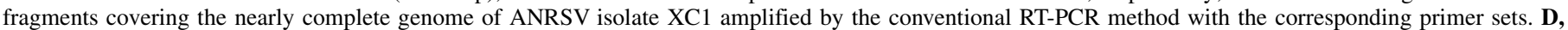

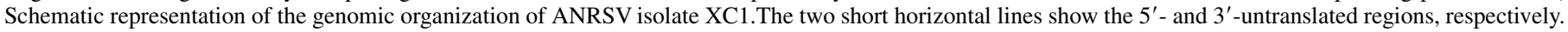

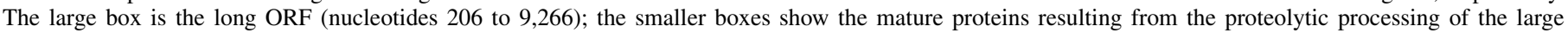

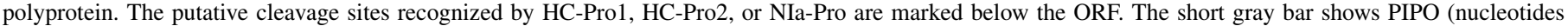
2,621 to 2,781 ) derived from RNA polymerase slippage on the P3 cistron. 
sequences of the polyprotein of ANRSV isolate XC1, ANSSV, all seven reported macluraviruses, and 37 representative members classified in the other nine definitive genera of the family Potyviridae were selected, essentially as previously published (Gao et al. 2018; Hu et al. 2018).

Development of an RT-PCR assay for ANRSV-specific detection. The nucleotide sequences of the CP gene of 27 ANRSV isolates in this study (Table 1) were completely aligned using the ClustalW2 online program to design ANRSV-specific primers for RT-PCR detection of ANRSV. Two primer sets (CP-F1/CP-R1 and $\mathrm{CP}-\mathrm{F} 2 / \mathrm{CP}-\mathrm{R} 2$ ) were designed on the basis of conserved regions of the CP gene of all ANRSV isolates. The presence of ANRSV was tested using RT-PCR assays with primer sets CP-F1/CP-R1 and CP-F2/CP-R2 amplifying PCR products of 455 and $367 \mathrm{bp}$, respectively.

\section{RESULTS}

Occurrence and prevalence of ANRSD in Hainan Province, China. In June 2017, ANRSD was first observed in an areca palm orchard in Qionghai (Fig. 1). The diseased trees (approximately 8 years old) exhibited necrotic ringspot symptoms in the medium and bottom leaves. However, no visual symptoms were shown in the top leaves (Fig. 2A). To investigate the occurrence and prevalence of ANRSD, we conducted a comprehensive field survey of the incidence of ANRSD in the eight main growing regions of areca palm in Hainan, China: Dingan, Qionghai, Wanning, Lingshui, Baoting, Qiongzhong, Ledong, and Sanya (Fig. 1). Our survey results showed that ANRSD was highly endemic in Hainan, with an average incidence rate of 19\%. Except for the Sanya and Ledong regions, ANRSD was observed to occur in all of the other six growing regions. Among them, ANRSD was highly endemic in Wanning, Dingan, and Qionghai, with incidence levels of 46, 45, and 36\%, respectively (Fig. 1).

A viral agent within the family Potyviridae was identified from a diseased areca palm. ANRSD has typical characteristics of viral diseases, such as necrotic ringspot symptoms (Fig. 2A). It is suspected that the potential causal agent of ANRSD might be a viral pathogen. To verify this hypothesis, crude extracts of leaf samples from a diseased areca palm plant (XC1) were subjected to an initial screening of the potential viral agent by transmission electron microscopy. Viral flexuous filamentous particles with a size of $\sim 15 \times 780 \mathrm{~nm}$ were observed (Fig. 2B). For the convenience of description, hereafter the characterized viral agent was tentatively named ANRSV.

To determine the genome sequences of the viral agent, we conducted high-throughput sequencing of sRNAs. Illumina sequencing yielded 29,143,383 high-quality reads (Supplementary Table S2). A total of 723 contigs were assembled de novo and were subjected to BLASTx search against the GenBank nonredundant protein database. The 24 contigs with sizes ranging from 65 to $599 \mathrm{bp}$ encoded proteins that shared high identity with the protein sequences of viruses in the family Potyviridae, ranging from 28 to 75\% amino acid identities (Supplementary Table S3). Notably, 18 of them were most closely related to viruses in the genus Macluravirus, such as artichoke latent virus, narcissus latent virus, and broad-leafed dock virus A (BDVA). Collectively, the above data suggest the viral agent, identified from the diseased areca palm tree (XC1), to be a member within the family Potyviridae.

To sequence the entire genome of ANRSV isolate $\mathrm{XC1}$, nine fragments covering the nearly complete genome were amplified using RT-PCR (Fig. 2C). In addition, two other fragments, representing the products of 5 ' - and 3 '-RACE, respectively, were also obtained (Fig. 2C). The overlapping sequences of these 11 fragments were assembled to generate the complete 9,434-nt genome sequence of ANRSV, excluding the poly(A) tail (Fig. 2D). The obtained sequence was deposited into the GenBank database with the accession number MH395371.

An sRNA mapping analysis showed that a total of $1,609,873$ reads, accounting for $5.52 \%$ of the total high-quality sRNAs, matched exactly with the genome sequence of the ANRSV isolate $\mathrm{XC1}$. The numbers of virus-derived sRNAs mapped onto the positive- and antisense genome of ANRSV were 1,062,691 and 547,182 , respectively.

The genome annotation reveals the existence of two cysteine proteinases in tandem (HC-Pro1 and $\mathrm{HC}$-Pro2) in the genomic 5' terminus of ANRSV. ORF analysis showed that the complete genome of ANRSV contains a large ORF (9,060 nt), encoding a polyprotein of 3,019 amino acids, flanked by a 5'-UTR of $205 \mathrm{nt}$ and a 3'-UTR of $169 \mathrm{nt}$ (Fig. 2D). Like the majority of viruses of the family Potyviridae, a CD search showed that the polyprotein of ANRSV has a conserved organization in the central and carboxy-terminal region. However, the amino terminus of the polyprotein contained two conserved cysteine proteinase domains of the peptidase_C6 super family (cl20022) (Fig. 3A). Both domains, corresponding to amino acids 154 to 240 and 456 to 560 , respectively, showed an actual alignment with the superfamily member pfam00851, with e-values of $2.73 \mathrm{e}-04$ and $1.26 \mathrm{e}-09$, respectively (Fig. 3A). The pfam00851 domain model was generated on the basis of multiple alignment of HC-Pro amino acid sequences of two potyviruses (i.e., potato virus Y [gi410516893] and sweet potato mild mottle virus [gi 81984821]) and one rymovirus (ryegrass mosaic virus [gi 81983955]). Therefore, herein the two putative cysteine proteases, containing the above domain, were named HC-Pro1 and HC-Pro2, respectively (Fig. 3A). To further characterize the catalytic activity sites of HC-Pro1 and HC-Pro2, sequences of their protease domains were compared with those of other representative viruses in the family Potyviridae (Fig. 3B). The three amino acid residues glycine, cysteine, and histidine corresponding to the putative catalytic

TABLE 1. Origins and coat protein GenBank accession numbers of areca palm necrosis ringspot virus isolates identified in this study for phylogenetic analysis

\begin{tabular}{|c|c|c|c|c|c|}
\hline Isolate $^{\mathrm{a}}$ & Region & Accession number & Isolate & Region & Accession number \\
\hline DA1 & Dingan & MH395372 & $\mathrm{XC} 2$ & Qionghai & MH425890 \\
\hline DA2 & Dingan & MH395373 & LG2 & Wanning & MH395379 \\
\hline DA3 & Dingan & MH395374 & MK1 & Wanning & MH395380 \\
\hline $\mathrm{NH} 2$ & Dingan & MH395385 & MK3 & Wanning & MH395382 \\
\hline DH1 & Qionghai & MH395375 & MK4 & Wanning & MH395383 \\
\hline DH2 & Qionghai & MH395376 & NY1 & Wanning & MH395386 \\
\hline DH4 & Qionghai & MH395377 & NY2 & Wanning & MH395387 \\
\hline SB4 & Qionghai & MH395391 & NY5 & Wanning & MH395389 \\
\hline SB5 & Qionghai & MH395392 & NP2 & Lingshui & MH425893 \\
\hline SB6 & Qionghai & MH395393 & NP3 & Lingshui & MH425894 \\
\hline $\mathrm{XC1}$ & Qionghai & MH395371 & & & \\
\hline
\end{tabular}

${ }^{a}$ Each isolate was identified from an individual areca palm tree. XC1 was collected in June 2017, and the others in October 2017. 
activity sites, which are extremely conserved for all viruses in the family Potyviridae, were predicted to be present in either HC-Pro1 or HC-Pro2 (Fig. 3B).

To identify the cleavage sites recognized by viral proteinases (HC-Pro1, HC-Pro2, and NIa-Pro), an amino acid sequence comparison of the polyprotein of ANRSV with those of the closely related macluraviruses was carried out. The results showed that nine conserved cleavage sites were predicted to be recognized by $\mathrm{HC}$ Pro1, HC-Pro2, or NIa-Pro (Supplementary Table S4), which contributed to the generation of 10 putative mature proteins (from the $\mathrm{N}$ terminus), denoted HC-Pro1, HC-Pro2, P3, 7K, CI, 9K, VPg, NIa-Pro, Nib, and CP (Fig. 2D). In addition, like all viruses of the family Potyviridae, a putative small ORF (PIPO) embedded within the P3 cistron was predicted (Fig. 2D).

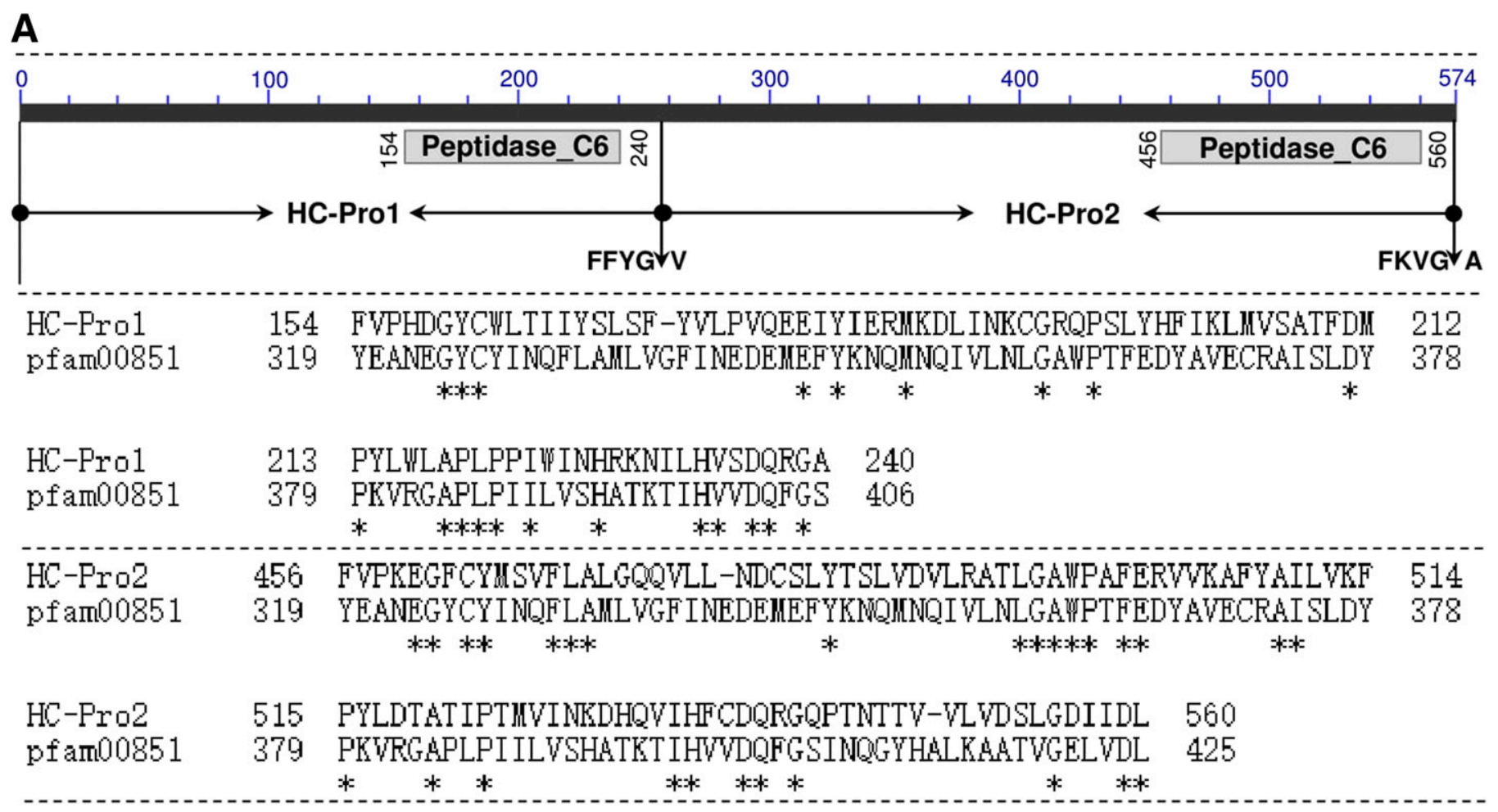

B

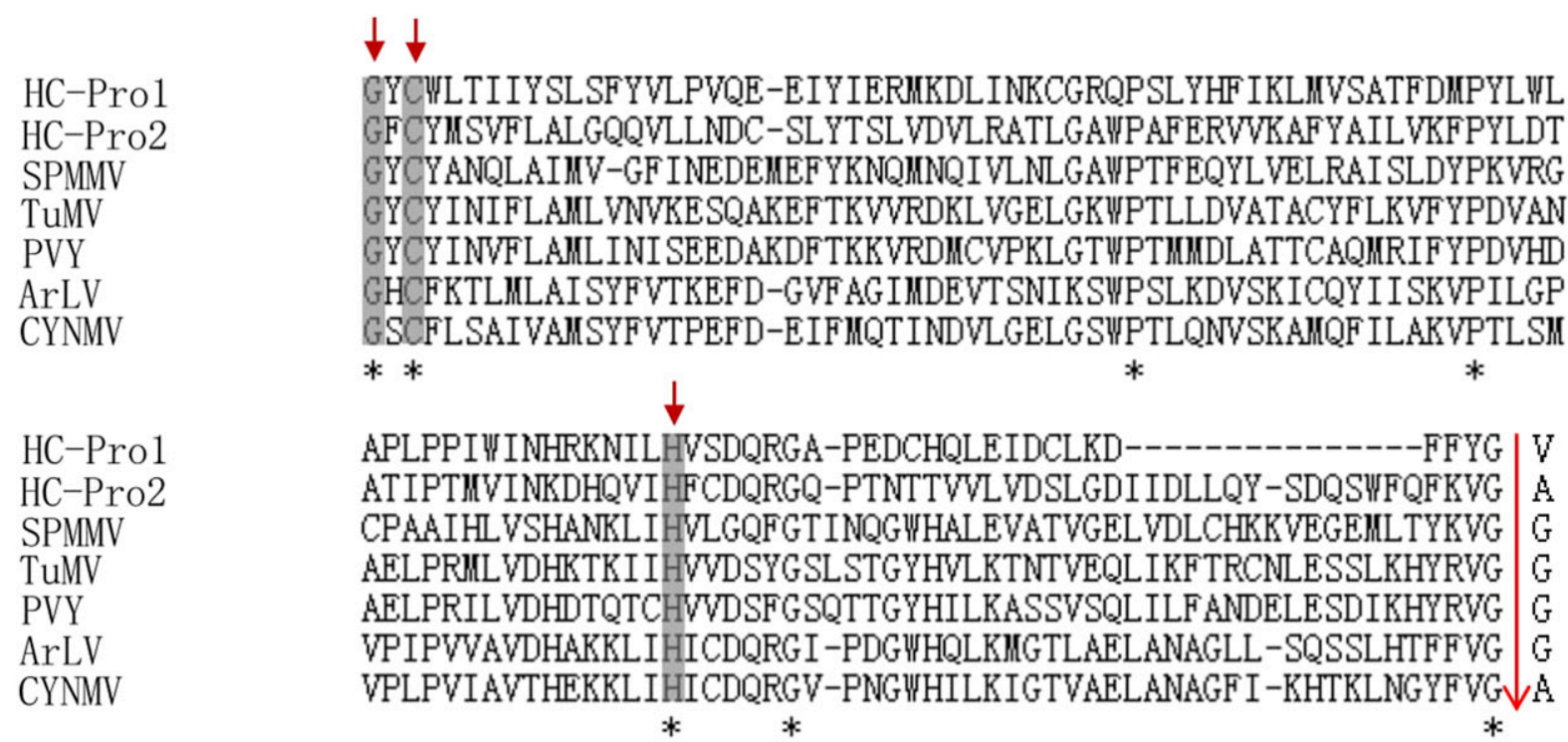

Fig. 3. Analysis of the conserved proteinase domains located in the amino terminus of the polyprotein of areca palm necrotic ringspot virus (ANRSV) isolate XC1. A, A conserved domain (CD) search of proteinase domains in the amino terminus of the polyprotein of ANRSV isolate XC1. A CD search revealed the existence of two conserved cysteine proteinase domains of the peptidase_C6 super family (accession number cl20022) in the amino terminus of the polyprotein of ANRSV (upper panel). The thick black line with the scales represents the schematic diagram of the amino terminus of the polyprotein. The identified peptidase_C6 domains are indicated by rectangles shaded in gray and delimited with positions of amino acid residues. The putative cleavage sites by HC-Pro1 and HC-Pro2 are indicated by vertical arrows. The middle and lower panels show that the actual alignment was detected with superfamily member pfam00851 for two regions delimited with amino acids 154 to 240 (middle) and amino acids 456 to 560 (lower), respectively. The identical amino acid residues are marked with asterisks. B, Comparison of the amino acid sequences of peptidase_C6 domains of HC-Pro1, HC-Pro2, and those of the representative viruses in the family Potyviridae. Asterisks mark the conserved amino acid residues among them. The three residues glycine, cysteine, and histidine, as the putative catalytic activity sites, which are extremely conserved for all viruses in the Potyviridae family, are predicted to be present either in both HC-Pro1 and HC-Pro2, and these residues are shaded in gray and indicated by arrows. The long vertical arrow marks the putative cleavage sites recognized by protease domains of the HC-Pro(s). SPMMV $=$ sweet potato mild mottle virus (NC_003797), TuMV = turnip mosaic virus (NC_002509), PVY = potato virus Y (NC_001616), ArLV = artichoke latent virus $(\mathrm{KP} 405232)$, and CYNMV = Chinese yam necrotic mosaic virus $(\mathrm{AB} 710145)$. 
Similar to other viruses within the family Potyviridae, the

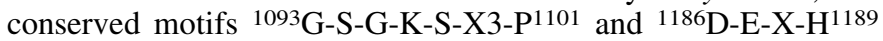
for helicase activity in CI (Sorel et al. 2014) were found. The NIb motif ${ }^{2579} \mathrm{GDD}^{2581}$, which is associated with replicase activity (Deng et al. 2015; Hong and Hunt 1996), was also found. In addition, the four active site residues of $\mathrm{H}^{1960}$, $\mathrm{D}^{1992}, \mathrm{C}^{2060}$, and $\mathrm{H}^{2076}$, with ${ }^{2058} \mathrm{G}-\mathrm{X}-\mathrm{C}-\mathrm{G}^{2061}$ around the active site cysteine, were found in NIa-Pro (Adams et al. 2005).

Sequence comparison and phylogenetic analysis clustered ANRSV in a recently proposed genus Arepavirus within the family Potyviridae. To examine the taxonomic status

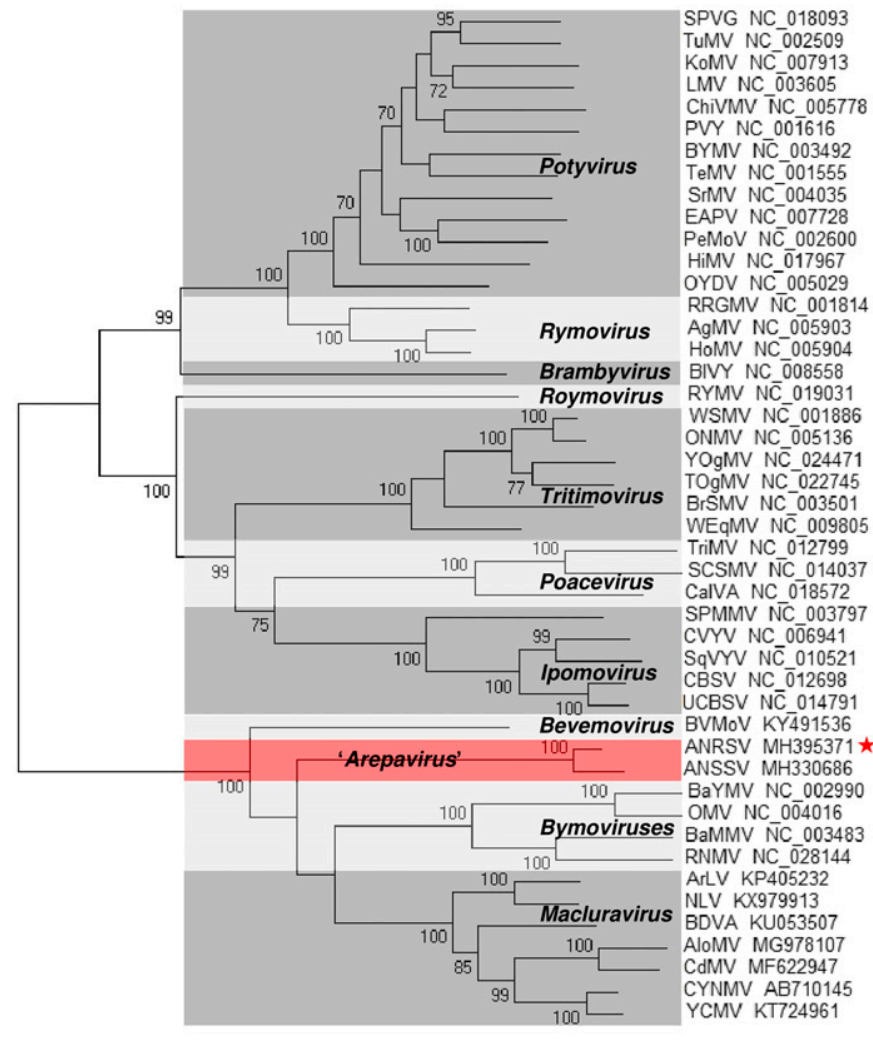

0.5

Fig. 4. Phylogenetic analysis of amino acid sequences of the polyprotein of areca palm necrotic ringspot virus (ANRSV) and areca palm necrotic spindle-spot virus (ANSSV), of all seven reported macluraviruses, and of 37 representative members in the other nine definitive genera within the family Potyviridae. These sequences were aligned using ClustalX, and the phylogenetic tree was constructed with MEGA 7.0 and the maximum likelihood method. The numbers at the branch nodes indicate bootstrap support (1,000 replicates). Values below $70 \%$ are not shown. The bar represents 0.5 substitutions per site. The darker shaded clade represents the newly proposed genus Arepavirus in the family Potyviridae (Yang et al. 2018). ANRSV is highlighted with an asterisk. SPVG = sweet potato virus $G$, TuMV = turnip mosaic virus, KoMV = konjac mosaic virus, LMV = lettuce mosaic virus, ChiVMV $=$ chilli veinal mottle virus, $\mathrm{PVY}=$ potato virus $\mathrm{Y}$, BYMV = bean yellow mosaic virus, TeMV = telosma mosaic virus, SrMV = sorghum mosaic virus, EAPV = east Asian Passiflora virus, PeMoV = peanut mottle virus, HiMV = hippeastrum mosaic virus, OYDV = onion yellow dwarf virus, RRGMV = ryegrass mosaic virus, AgMV = agropyron mosaic virus, $\mathrm{HoMV}=$ hordeum mosaic virus, $\mathrm{BIVY}=$ blackberry virus $\mathrm{Y}, \mathrm{RYMV}=$ rose yellow mosaic virus, WSMV = wheat streak mosaic virus, ONMV = oat necrotic mottle virus, YOgMV = yellow oat grass mosaic virus, TOgMV = tall oatgrass mosaic virus, BrSMV = brome streak mosaic virus, WEqMV = wheat eqlid mosaic virus, TriMV = triticum mosaic virus, SCSMV = sugarcane streak mosaic virus, CalVA = caladenia virus $\mathrm{A}, \mathrm{SPMMV}=$ sweet potato mild mottle virus, CVYV = cucumber vein yellowing virus, SqVYV = squash vein yellowing virus, $\mathrm{CBSV}=$ cassava brown streak virus, UCBSV = ugandan cassava brown streak virus, $\mathrm{BVMoV}=$ bellflower veinal mottle virus, BaYMV = barley yellow mosaic virus, $\mathrm{OMV}=$ oat mosaic virus, BaMMV = barley mild mosaic virus, $\mathrm{RNMV}=$ rice necrosis mosaic virus, ArLV = artichoke latent virus, NLV = narcissus latent virus, BDVA = broad-leafed dock virus A, AloMV = alpinia oxyphylla mosaic virus, $\mathrm{CdMV}=$ cardamom mosaic virus, $\mathrm{CYNMV}=$ Chinese yam necrotic mosaic virus, and YCMV = yam chlorotic necrosis virus. of ANRSV, the polyprotein of ANRSV was subjected to BLASTp search against the GenBank nonredundant protein database. The results showed that the polyprotein of ANRSV shared maximum amino acid sequence identities of 31 to $33 \%$ (with 81 to $89 \%$ coverage) to those of all known seven macluraviruses, such as Chinese yam necrotic mosaic virus (KJ789135), cardamom mosaic virus (KX979913), yam chlorotic necrosis virus (MG755240), and BDVA (KU053507). Nucleotide sequence comparisons of ANRSV to these macluraviruses reveal identities ranging from 38.4 to $42.4 \%$, which is below the threshold for genus demarcation within the family Potyviridae (Adams et al. 2005b). Moreover, amino acid sequence comparison of each mature protein was performed via pairwise ClustalW2 analysis, and the results showed that the 7K, CI, $\mathrm{NIb}$, and $\mathrm{CP}$ proteins shared relatively high amino acid sequence identities ( 30.5 to $40.7 \%, 32.5$ to $36.9 \%, 41.3$ to $43.4 \%$, and 31.6 to $33.0 \%$, respectively), whereas lower identities were identified for P3 and 9K proteins (18.0 to $20.4 \%$ and 15.2 to $29.1 \%$, respectively) (Supplementary Table S5). Noticeably, the above analysis results were similar to those for ANSSV, a newly characterized virus from areca palm and representing the first member of a putative new genus, Arepavirus, in the family Potyviridae (Yang et al. 2018).

To further dissect the taxonomic classification of ANRSV, a phylogenetic analysis was performed using the amino acid sequences of the polyprotein of ANRSV and ANSSV, of the seven reported macluraviruses, and of 37 representative members of the other nine definitive genera in the family Potyviridae. Phylogenetic analysis firmly classified ANRSV together with ANSSV as a separate clade, supported by a bootstrap value of $100 \%$, firmly putting ANRSV in the recently proposed Arepavirus genus typified by ANSSV (Yang et al. 2018). The proposed Arepavirus genus is most closely related to three definitive genera: Macluravirus, Bymovirus, and Bevemovirus (Fig. 4). Moreover, genomic sequence comparisons between ANRSV and ANSSV were performed. ANSSV and ANRSV have a similar genome size (9,434 versus 9,437 nt) and genomic organization (Supplementary Table S6). For the polyprotein sequence, ANSSV and ANRSV share 72.5 and $76.2 \%$ identities at the nucleotide and amino acid levels, respectively. Among all putative mature proteins, $7 \mathrm{~K}, \mathrm{CI}$, and $\mathrm{CP}$ shared the highest amino acid sequence identities (90.0, 85.1, and $88.6 \%$, respectively), and $9 \mathrm{~K}$ and $\mathrm{P} 3$ shared the lowest ones (60.2 and $66.8 \%$, respectively). Thus, the polyprotein sequence identities between ANRSV and ANSSV are below the species demarcation criterion for the Potyviridae family, but the $\mathrm{CP}$ identity level is above the corresponding threshold (Adams et al. 2005b). The taxonomic relationship between ANRSV and ANSSV is therefore complex.

Phylogenetic relationship of ANRSV isolates. To understand the genetic diversity of ANRSV, complete CP gene sequences were determined from 27 ANRSV isolates (Table 1) and subjected to a phylogenetic analysis with ANSSV isolate "HNBT" as a reference sequence. Sequence analysis showed that all $\mathrm{CP}$ genes of ANRSV isolates have the same size of $843 \mathrm{nt}$, similar to that of ANSSV. Multiple sequence alignment showed that the CP genes of ANRSV isolates shared 91.6 to $100 \%$ nucleotide and 95.0 to $100 \%$ amino acid identities, but lower sequence identities with ANSSV ( 80.1 to $81.5 \%$ and 86.8 to $88.6 \%$ at the nucleotide and amino acid levels, respectively). Correspondingly, phylogenetic analysis showed that all ANRSV isolates were clearly separated from ANSSV (Fig. 5). In addition, two well-defined clusters were formed among ANRSV isolates according to the phylogenetic tree of the CP nucleotide sequences (Fig. 5). The isolate NY2 shared 91.6 to $93.2 \%$ nucleotide and 95.0 to $97.5 \%$ amino acid identities with the other isolates, representing a separate group. The other isolates with 93.1 to $100 \%$ nucleotide and 97.5 to $100 \%$ amino acid identities were clustered into group I (Fig. 5).

ANRSV is closely associated with the necrotic ringspot diseases in areca palm. To investigate whether ANRSV is associated with the necrotic ringspot symptoms in areca palm, we 
collected a total of 45 symptomatic and 20 asymptomatic samples from the eight regions of areca palm cultivation in Hainan. The samples were subjected to RT-PCR assays with two different primer sets: CP-F1/CP-R1 and CP-F2/CP-R2, respectively. The results showed that 43 of 45 symptomatic samples $(95.6 \%$ ) tested positive for ANRSV. All asymptomatic samples tested negative for ANRSV (Supplementary Fig. S1). These data support that ANRSV is closely associated with the development of necrotic ringspot symptoms in areca palm.

\section{DISCUSSION}

In this study, a survey revealed that a new disease with severe foliage necrotic ringspot symptoms in areca palm (ANRSD) is highly prevalent in the main growing regions in Hainan, China. A virus classified within a recently proposed genus Arepavirus of the family Potyviridae is closely associated with ANRSD. This does not exclude potential roles of other unknown factor(s) in the development of necrotic ringspot symptoms in areca palm, such as the cases for grapevine leafroll disease and mealybug wilt of pineapple disease (Almeida et al. 2013; Sether and Hu 2002). Therefore, an infectivity test in areca palm with either an infectious cDNA clone or purified viral particles is needed to fulfill Koch's postulates. The most pressing is to evaluate the impact of ANRSD on the growth and areca nut production of areca palm under field conditions.

In 2018, we reported another viral disease with slightly different symptoms ("spindle-spot") in a single areca palm. Different from ANRSD, the diseased areca palm shows chlorotic symptoms in new leaves and necrotic spindle-spots in medium and bottom leaves (Yang et al. 2018). A novel virus (ANSSV) was characterized from one spindle-spot sample (HNBT) and proposed to be the first member of a putative new genus Arepavirus of the family Potyviridae.

ANRSV and ANSSV are closely related, and their polyprotein sequence identity levels are below the threshold values for species demarcation in the family Potyviridae (Adams et al. 2005b). However, the $\mathrm{CP}$ sequence identity levels between the two agents are above the species cutoff (Adams et al. 2005b). The taxonomic situation of these two agents is therefore complex, as they may represent different strains of the same species or two novel viruses. To clarify this, additional characteristics of ANRSV and ANSSV, such as host range, symptomatology, serology, and transmission vector(s), need to be further investigated.

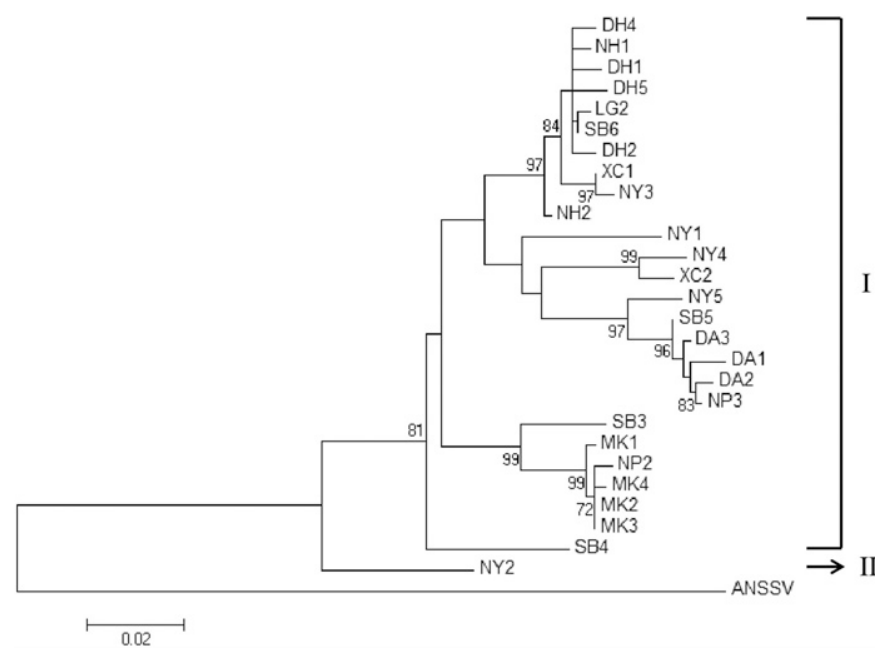

Fig. 5. Phylogenetic analysis based on the nucleotide sequences of coat protein genes of areca palm necrosis ringspot virus (ANRSV) isolates identified in this study. The GenBank accession numbers of these sequences are listed in Table 1. Areca palm necrosis ringspot virus (ANSSV) isolate "HNBT" (GenBank accession number MH330686), the first member of the newly proposed genus Arepavirus of the family Potyviridae, is used as a reference sequence. These sequences were completely aligned using ClustalX, and the phylogenetic tree was constructed with MEGA 7.0 and the maximum likelihood method. The numbers at the branch nodes indicate bootstrap support (1,000 replicates). Values below $70 \%$ are not shown. The bar represents 0.02 substitutions per site.
More than $80 \%$ of plant viruses depend on insect vectors for transmission (Hohn 2007). With regard to the family Potyviridae, viruses of six genera are spread between host plants by arthropods (i.e., potyviruses and macluraviruses by aphids, ipomoviruses by whiteflies, and poaceviruses, rymoviruses, and tritimoviruses by mites), and bymoviruses are transmitted by fungi (Polymyxa graminis). The transmission vectors for viruses of the remaining three genera (i.e., Brambyvirus, Roymovirus, and Bevemovirus) have not been confirmed (Wylie et al. 2017a, 2017b). Considering the high prevalence of ANRSD, it is believed that the transmission of ANRSV between host plants in the field could be vectored by insects. During our field survey, five insect species (i.e., B. longissima, T. rufivena, Aleurocanthus spiniferus, Aspidiotus destructor Signoret, and Opisina arenosella) severely affected areca palms. Therefore, screening and identification of the transmission vector of ANRSV from the above insect species will be carried out.

For viruses in the family Potyviridae, the genomic N-terminal regions are highly variable and encode one or two leader proteinases that are released from the polyprotein precursors by self-cleavage. The serine and cysteine proteinases in tandem (P1 and HC-Pro) are encoded by the genomic N-termini of the majority of viruses in the family Potyviridae, such as potyviruses, rymoviruses, tritivimoviruses, poaceviruses, brambyviruses, roymoviruses, and some of the ipomoviruses (Adams et al. 2005b; Mollov et al. 2013; Revers and García 2015; Valli et al. 2017; Wylie et al. 2017a, b). A single leader proteinase is identified for macluraviruses (HC-Pro), bevemoviruses (HC-Pro), and some of the ipomoviruses (P1) (Revers and García 2015; Seo et al. 2017; Valli et al. 2017). Two serine proteinases in tandem (P1a and P1b) are identified for other ipomoviruses, such as cucumber vein yellowing virus and squash vein yellowing virus (Revers and García 2015; Valli et al. 2017). The genome annotation suggests that the 5 '-terminal genome part of ANRSV encodes two cysteine proteases in tandem (HC-Pro1 and HC-Pro2) (Fig. 3). Because biological activities for the leader proteinases (e.g., RSS for HC-Pro and host adaption for P1) are mainly attributed to the amino- and central regions of the proteinases for several well-studied viruses (Pasin et al. 2014; Rodamilans et al. 2013; Shan et al. 2015, 2018), it is reasonable to speculate that the highly divergent regions between HC-Pro1 and HC-Pro2 (Supplementary Fig. S2) likely contribute to their functional differences. Consequently, dissecting the functional roles of HC-Pro1 and HC-Pro2, such as RSS activity, host adaption, and involvement in transmission by vector(s), will address our understanding of the biological relevance of the hypervariable genomic 5' terminus of viruses in the family.

In this study, we developed RT-PCR assays for the efficient detection of ANRSV using primer sets CP-F1/CP-R1 and CP-F2/ $\mathrm{CP}-\mathrm{R} 2$, respectively. Through RT-PCR detection of ANRSV from 45 symptomatic and 20 asymptomatic areca palm plants, a strong association between ANRSV and ANRSD was found. However, two symptomatic trees tested negative for ANRSV. A possible explanation could be the molecular variability of the CP gene between different ANRSV isolates (strains).

In summary, in this study we report that ANRSD is closely associated with a virus (ANRSV) and is highly prevalent in the main growing regions in Hainan, China. ANRSV is a close relative of the recently characterized ANSSV, and similarly belongs to the recently proposed genus Arepavirus in the family Potyviridae. Attempts to decipher the functional roles of the HC-Pro1 and HC-Pro2 proteins of ANRSV, such as RSS activity and involvement in vector-mediated viral transmission, will advance our understanding of the evolutionary relationship among viruses in the family Potyviridae.

\section{ACKNOWLEDGMENTS}

We thank W. Qiu (W. H. Darr College of Agriculture, Missouri State University) for critical reading and two anonymous reviewers for constructive and helpful suggestions to improve the manuscript. 


\section{LITERATURE CITED}

Adams, M. J., Antoniw, J. F., and Beaudoin, F. 2005a. Overview and analysis of the polyprotein cleavage sites in the family Potyviridae. Mol. Plant Pathol. 6:471-487.

Adams, M. J., Antoniw, J. F., and Fauquet, C. M. 2005b. Molecular criteria for genus and species discrimination within the family Potyviridae. Arch. Virol. 150:459-479.

Almeida, R. P., Daane, K. M., Bell, V., Blaisdell, G. K., Cooper, M. L., Herrbach, E., and Pietersen, G. 2013. Ecology and management of grapevine leafroll disease. Front. Microbiol. 4:94.

Amudhan, M. S., Begum, V. H., and Hebbar, K. B. 2012. A review on phytochemical and pharmacological potential of Areca catechu L. seed. Int. J. Pharm. Sci. Res. 3:4151-4157.

Chung, B. Y., Miller, W. A., Atkins, J. F., and Firth, A. E. 2008. An overlapping essential gene in the Potyviridae. Proc. Natl. Acad. Sci. USA 105: 5897-5902.

Deng, P., Wu, Z., and Wang, A. 2015. The multifunctional protein CI of potyviruses plays interlinked and distinct roles in viral genome replication and intercellular movement. Virol. J. 12:141.

Gao, F., Shen, J., Liao, F., Cai, W., Lin, S., Yang, H., and Chen, S. 2018. The first complete genome sequence of narcissus latent virus from Narcissus. Arch. Virol. 163:1383-1386.

Heatubun, C. D., Dransfield, J., Flynn, T., Tjitrosoedirdjo, S. S., Mogea, J. P., and Baker, W. 2012. A monograph of the betel nut palms (Areca: Arecaceae) of East Malesia. Bot. J. Linn. Soc. 168:147-173.

Hohn, T. 2007. Plant virus transmission from the insect point of view. Proc. Natl. Acad. Sci. USA 104:17905-17906.

Hong, Y., and Hunt, A. G. 1996. RNA polymerase activity catalyzed by a potyvirus-encoded RNA-dependent RNA polymerase. Virology 226: 146-151.

Hu, W., Li, Z., Wang, X., Liu, W., Huang, C., Miao, W., and Cui, H. 2018. Complete genomic sequence of a novel macluravirus, alpinia oxyphylla mosaic virus (AloMV), identified in Alpinia oxyphylla. Arch. Virol. 163: 2579-2582.

Kanatiwela-de Silva, C. K., Damayanthi, M., de Silva, R., Dickinson, M., de Silva, N., and Udagama, P. 2015. Molecular and scanning electron microscopic proof of phytoplasma associated with areca palm yellow leaf disease in Sri Lanka. Plant Dis. 99:1641.

Li, H., Dong, Y., Chang, J., He, J., Chen, H., Liu, Q. 2016a. High-throughput microRNA and mRNA sequencing reveals that microRNAs may be involved in melatonin-mediated cold tolerance in Citrullus lanatus L. Front. Plant Sci. 7:1231.

Li, J., Zheng, H., Zhang, C., Han, K., Wang, S., Peng, J., Lu, Y., Zhao, J., Xu, P., Wu, X., Li, G., Chen, J., and Yan, F. 2016b. Different virus-derived siRNAs profiles between leaves and fruits in cucumber green mottle mosaic virus-infected Lagenaria siceraria plants. Front. Microbiol. 7:1797.

Lockhart, B., Zlesak, D., and Fetzer, J. 2011. Identification and partial characterization of six new viruses of cultivated roses in the USA. Acta Hortic.: 139-147.

Marchlerbauer, A., Bo, Y., Han, L., He, J., Lanczycki, C. J., Lu, S., Chitsaz, F., Derbyshire, M. K., Geer, R. C., Gonzales, N. R., Gwadz, M., Hurwitz, D. I., Lu, F., Marchler, G. H., Song, J. S., Thanki, N., Wang, Z., Yamashita, R. A., Zhang, D., Zheng, C., Geer, L. Y., and Bryant, S. H. 2017. CDD/SPARCLE: Functional classification of proteins via subfamily domain architectures. Nucleic Acids Res. 45:D200-D203.

Minutillo, S. A., Marais, A., Mascia, T., Faure, C., Svanelladumas, L., Theil, S., Payet, A., Perennec, S., Schoen, L., Gallitelli, D., and Candresse, T. 2015. Complete nucleotide sequence of Artichoke latent virus shows it to be a member of the genus Macluravirus in the family Potyviridae. Phytopathology 105:1155-1160.

Mollov, D., Lockhart, B., and Zlesak, D. 2013. Complete nucleotide sequence of rose yellow mosaic virus, a novel member of the family Potyviridae. Arch. Virol. 158:1917-1923.

Olspert, A., Chung, B. Y., Atkins, J. F., Carr, J. P., and Firth, A. E. 2015. Transcriptional slippage in the positive-sense RNA virus family Potyviridae. EMBO Rep. 16:995-1004.

Pasin, F., Simón-Mateo, C., and García, J. A. 2014. The hypervariable aminoterminus of P1 protease modulates potyviral replication and host defense responses. PLoS Pathog 10:e1003985.

Peng, W., Liu, Y., Wu, N., Sun, T., He, X., Gao, Y., and Wu, C. 2015. Areca catechu L. (Arecaceae): A review of its traditional uses, botany, phytochemistry, pharmacology and toxicology. J. Ethnopharmacol. 164: $340-356$.
Ramaswamy, M., Nair, S., Soumya, V. P., and Thomas, G. V. 2013. Phylogenetic analysis identifies a 'Candidatus Phytoplasma oryzae'-related strain associated with yellow leaf disease of areca palm (Areca catechu L.) in India. Int. J. Syst. Evol. Microbiol. 63:1376-1382.

Rawlings, N. D., Barrett, A. J., and Finn, R. 2016. Twenty years of the MEROPS database of proteolytic enzymes, their substrates and inhibitors. Nucleic Acids Res.: D343-D350.

Revers, F., and García, J. A. 2015. Molecular biology of potyviruses. Adv. Virus Res. 92:101-199.

Rodamilans, B., Valli, A., and Garcia, J. A. 2013. Mechanistic divergence between P1 proteases of the family Potyviridae. J. Gen. Virol. 94: 1407-1414.

Rodamilans, B., Valli, A., Mingot, A., San León, D., Baulcombe, D., López-Moya, J. J., and García, J. A. 2015. RNA polymerase slippage as a mechanism for the production of frameshift gene products in plant viruses of the Potyviridae family. J. Virol. 89:6965-6967.

Rohožková, J., and Navratil, M. 2011. P1 peptidase - a mysterious protein of family Potyviridae. J. Biosci. 36:189-200.

Seo, J. K., Kwak, H. R., Kim, M. K., Kim, J. S., and Choi, H. S. 2017. The complete genome sequence of a novel virus, bellflower veinal mottle virus, suggests the existence of a new genus within the family Potyviridae. Arch. Virol. 162:2457-2461

Sether, D. M., and Hu, J. S. 2002. Yield impact and spread of Pineapple mealybug wilt associated virus- 2 and mealybug wilt of pineapple in Hawaii. Plant Dis. 86:867-874.

Shan, H., Pasin, F., Tzanetakis, I. E., Simonmateo, C., Garcia, J. A., and Rodamilans, B. 2018. Truncation of a P1 leader proteinase facilitates potyvirus replication in a non-permissive host. Mol. Plant Pathol. 19: 1504-1510.

Shan, H., Pasin, F., Valli, A., Castillo, C., Rajulu, C., Carbonell, A., Simón-Mateo, C., García, J. A., and Rodamilans, B. 2015. The Potyviridae $\mathrm{P} 1 \mathrm{a}$ leader protease contributes to host range specificity. Virology 476: 264-270.

Sorel, M., Garcia, J. A., and Germanretana, S. 2014. The Potyviridae cylindrical inclusion helicase: A key multipartner and multifunctional protein. Mol. Plant-Microbe Interact. 27:215-226.

Tatineni, S., Qu, F., Li, R., Morris, T. J., and French, R. 2012. Triticum mosaic poacevirus enlists $\mathrm{P} 1$ rather than HC-Pro to suppress RNA silencingmediated host defense. Virology 433:104-115.

Valli, A., Gallo, A., Rodamilans, B., Lópezmoya, J. J., and García, J. A. 2017. The HCPro from the Potyviridae family: An enviable multitasking helper component that every virus would like to have. Mol. Plant Pathol. 19: 744-763.

Valli, A., López-Moya, J. J., and García, J. A. 2007. Recombination and gene duplication in the evolutionary diversification of $\mathrm{P} 1$ proteins in the family Potyviridae. J. Gen. Virol. 88:1016-1028.

Wylie, S. J., Adams, M., Chalam, C., Kreuze, J., López-Moya, J. J., Ohshima, K., Praveen, S., Rabenstein, F., Stenger, D., Wang, A., and Zerbini, F. M., and ICTV Report Consortium. 2017a. Virus taxonomy profile: Potyviridae. J. Gen. Virol. 98:352-354.

Wylie, S. J., Adams, M., Chalam, C., Kreuze, J., López-Moya, J. J., Ohshima, K., Praveen, S., Rabenstein, F., Stenger, D., Wang, A., and Zerbini, F. M., and ICTV Report Consortium. 2017b. Erratum: ICTV virus taxonomy profile: Potyviridae. J. Gen. Virol. 98:2893.

Yang, K., Ran, M. Y., Li, Z. P., Hu, M. J., Zheng, L., Liu, W. B., Jin, P. F., Miao, W. G., Shen, W. T., and Cui, H. G. 2018. Analysis of the complete genomic sequence of a novel virus, areca palm necrotic spindle-spot virus, reveals the existence of a new genus in the family Potyviridae. Arch. Virol. 163:3471-3475.

Young, B. A., Stenger, D. C., Qu, F., Morris, T. J., Tatineni, S., and French, R. 2012. Tritimovirus P1 functions as a suppressor of RNA silencing and an enhancer of disease symptoms. Virus Res. 163:672-677.

Yu, H., Qi, S., Chang, Z., Rong, Q., Akinyemi, I. A., and Wu, Q. 2015. Complete genome sequence of a novel velarivirus infecting areca palm in China. Arch. Virol. 160:2367-2370.

Zerbino, D. R., and Birney, E. 2008. Velvet: Algorithms for de novo short read assembly using de Bruijn graphs. Genome Res. 18:821-829.

Zhang, X., Tang, B., and Hou, Y. 2015. A rapid diagnostic technique to discriminate between two pests of palms, Brontispa longissima and Octodonta nipae (Coleoptera: Chrysomelidae), for quarantine applications. J. Econ. Entomol. 108:95-99.

Zhong, B., Lv, C., and Qin, W. 2017. Effect of temperature on the population growth of Tirathaba rufivena (Lepidoptera: Pyralidae) on Areca catechu (Arecaceae). Fla. Entomol. 100:578-582. 